Journal of Foreign

Language leaching

and Applied linguistics

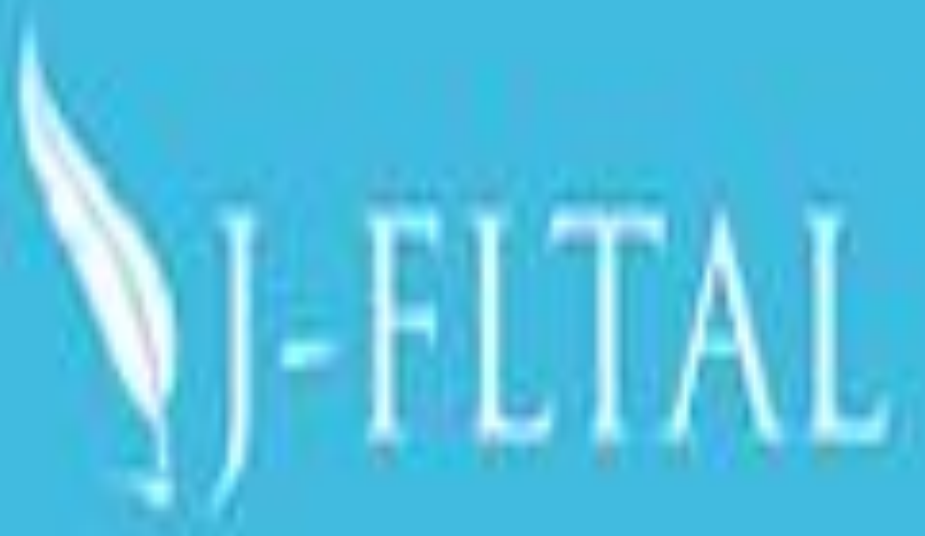


- Akbarov, A., \& Turker, L. (2015) Complex Predicate Constructions in Uzbek Language. Journal of Foreign Language Teaching and Applied Linguistics, 2(2). ISSN 2303-5528

- Barišić, A. T. (2015) POGLED NA STILSKE FIGURE PRIPOVIJETKE MRAK NA SVIJETLIM STAZAMA IVANA GORANA KOVAČICA. Journal of Foreign Language Teaching and Applied Linguistics, 2(2). ISSN 2303-5528

- Borriello, G. (2015) "KOKUJI (国字): THE JAPANESE “NATIONAL CHARACTERS”. Journal of Foreign Language Teaching and Applied Linguistics, 2(2). ISSN 2303-5528

- Ćatibušić, B. (2015) THE ACQUISITION OF ENGLISH L2 BY IMMIGRANT CHILDREN: EAL AND INTERCULTURAL EDUCATION IN MULTILINGUAL IRELAND. Journal of Foreign Language Teaching and Applied Linguistics, 2(2). ISSN 2303-5528

- Čubela, R. (2015) (RE)CONSTRUCTION OF NATIONALISM IN BOSNIA AND HERZEGOVINA INSTRUMENTALISATION OF LANGUAGE IN THE ONLINE-MEDIA FOR PROMOTING

NATIONALISM. Journal of Foreign Language Teaching and Applied Linguistics, 2(2). ISSN 2303-5528

- Doko, F. (2015) HEMINGWAY AND KADARE - A COMPARATIVE OUTLINE. Journal of Foreign Language Teaching and Applied Linguistics, 2(2). ISSN 2303-5528

- Grabar, I., Kostina , E., \& Kolednjak, M. (2015) LOVE AND HATRED IN TWO LANGUAGES: CROSSCULTURAL ANALYSIS. Journal of Foreign Language Teaching and Applied Linguistics, 2(2). ISSN 2303-5528

- Güvenç, S. (2015) A CASE STUDY: EFL LEARNERS' AND WRITING TEACHERS' ATTITUDES TOWARDS PERFORMANCE BASED PORTFOLIO IN A UNIVERSITY CONTEXT. Journal of Foreign Language Teaching and Applied Linguistics, 2(2). ISSN 2303-5528

- Kostić, N. (2015) WORD CLASS AND TEXTUAL FUNCTIONS OF ANTONYMS: A CORPUS STUDY. . Journal of Foreign Language Teaching and Applied Linguistics, 2(2). ISSN 2303-5528

- Kryeziu, L. (2015) LANGUAGE AND GENDER DIFFERENCE IN DISCOURSE. Journal of Foreign Language Teaching and Applied Linguistics, 2(2). ISSN 2303-5528

- Kucukalic, L. (2015) EXTENDING BEYOND THE CLASSROOM: SEMIOTICS AND CULTURE IN EFL COURSES. Journal of Foreign Language Teaching and Applied Linguistics, 2(2). ISSN 2303-5528

- Langacker, R. W. (2015) How to Build an English Clause. Journal of Foreign Language Teaching and Applied Linguistics, 2(2). ISSN 2303-5528

- Petrovska, L., \& Dugandžić, A. (2015) CONCEPT FOR UKRAINIAN LANGUAGE TEXTBOOK FOR CROATIAN STUDENTS (IN TERMS OF LEARNING A CLOSELY RELATED LANGUAGE). Journal of Foreign Language Teaching and Applied Linguistics, 2(2). ISSN 2303-5528

- Šrić, I., \& Levačić , P. (2015) “THE MAP IS MORE INTERESTING THAN THE TERRITORY” THE CASE OF THE NOVEL THE MAP AND THE TERRITORY BY MICHEL HOUELLEBECQ. Journal of Foreign Language Teaching and Applied Linguistics, 2(2). ISSN 2303-5528

- Shabani, E. (2015) ARSCOMBINATORIA IN THE NOVEL “THE NAME OF THE ROSE” BY UMBERTO ECO. Journal of Foreign Language Teaching and Applied Linguistics, 2(2). ISSN 2303-5528

- Sherwin, H. (2015) DEVELOPING BEGINNER TEACHERS' PROBLEM SOLVING SKILLS IN POST-LESSON REFLECTIONS. Journal of Foreign Language Teaching and Applied Linguistics, 2(2). ISSN 2303-5528

- Tsapikidou, D. (2015) THE EFFECTS OF INTEGRATED FFI AND ISOLATED FFI ON THE ACQUISITION OF THE ENGLISH PAST TENSE. Journal of Foreign Language Teaching and Applied Linguistics, 2(2). ISSN 2303-5528

- Vulović, L. (2015) TERMINI OZNAČAVANJA "BASME/BAJALICE" U SAVREMENOM GRČKOM JEZIKU. Journal of Foreign Language Teaching and Applied Linguistics, 2(2). ISSN 2303-5528

- Wlosowicz, T. M. (2015) THE ATTRITION OF PORTUGUESE AS A THIRD OR ADDITIONAL LANGUAGE OVER THE SUMMER HOLIDAYS. Journal of Foreign Language Teaching and Applied Linguistics, 2(2). ISSN 2303-5528 


\title{
Assessing Pragmatic Competence Of L2 Learners
}

\section{Marija Kusevska \& Tatjana Ulanska \& Biljana Ivanovska \& Nina Daskalovska \& Liljana \\ Mitkovska}

University Goce Delchev-Stip \& FON University

\begin{abstract}
The purpose of this paper is to explore the components of pragmatic competence for L2 learners. Developing pragmatic competence in a second/foreign language has been addressed in many articles and publications on cross-cultural and interlanguage pragmatics (Bardovi-Harlig, 1999; Barron, 2003; BlumKulka, House, \& Kasper, 1989; Cohen \& Ishihara, 2005; Ishihara \& Cohen, 2010; Kasper \& Blum-Kulka, 1993; McConachy \& Hata, 2013; Trosborg, 2010; Wigglesworth \& Yates, 2007; etc.). The Common European Framework of Reference for Languages (Council of Europe, 2001) also addresses this issue. Their stance is that communicative language competences include linguistic, sociolinguistic and pragmatic competences. Pragmatic competence itself includes learner's knowledge of the principles according to which messages are: a. organized, structured and arranged (discourse competence); $b$. used to perform communicative functions (functional competence); $c$. sequenced according to interactional and transactional schemata (design competence) (Council of Europe, 2001, p. 123). Roever (2005) chose three components for his web-based test of pragmatic competence: speech acts, implicatures and routines. Research on interlanguage pragmatics often focuses on speech acts, politeness, use of formulaic expressions, mitigation, etc.

In determining L2 learner's pragmatic competence we face two major problems:

1. what components of learner's interlanguage to measure; and

2. how to measure them.

In this paper, we first define interlanguage pragmatics. Then we refer to issues referring to pragmatic competence and components that are relevant for its development. Finally, we discuss instruments and methods of testing interlanguage pragmatic competence.
\end{abstract} Key words: interlanguage, speech acts, pragmatic competence, L2 learners

Article History:

Submitted: 08.06.2015

Accepted: 08.08.2015

DOI: $10.14706 / J F L T A L 152312$ 
Assessing Pragmatic Competence Of L2 Learners

150

Introduction 
The main focus of this paper is on the components of pragmatic competence of L2 learners and their assessment. It resulted from a research related to the project "The role of explicit instruction in developing pragmatic competence in learning English and German as a foreign language." The participants in the project are students of English and German at the Faculty of Philology at Goce Delcev University in Stip, Republic of Macedonia. The project was motivated by the importance of pragmatic knowledge, which allows learners to adequately communicate in the target language.

The main goals of teaching foreign languages have long been preparing learners to communicate effectively in the language they are learning. Followers of the Communicative Method for decades have been highlighting the fact that knowledge of vocabulary and grammatical structures is not enough for successful communication in the target language. Learners need to be trained to choose the right linguistic means with reference to their interlocutors and their relationship with them. Having in mind this goal of language instruction, we may expect pragmatics to have the leading role in language learning and teaching. Unfortunately, it remains on the margins of foreign language teaching. In language learning textbooks it is represented only as much as it is necessary so that authors are not blamed for not following the modern approaches to language learning and still holding firmly to the traditional way in which grammar is most important, vocabulary is second, and there is a miscellaneous mixture of other areas, including pragmatics.

\section{Literature review in defining interlanguge pragmatics}

There is a long tradition of research into cross-cultural and interlanguage pragmatics in which researchers address the issue of developing pragmatic competence in a foreign/ second language (BardoviHarlig, 1999; Barron, 2003; Blum-Kulka, House, \& Kasper, 1989; Cohen \& Ishihara, 2005; Ishihara \& Cohen, 2010; Kasper \& Blum-Kulka, 1993; McConachy \& Hata, 2013; Trosborg, 2010; Wigglesworth \& Yates, 2007; etc.).

Interlanguage pragmatics has been perceived and defined in various ways by researchers. The learner's pragmatic ability according to Kasper and Blum-Kulka (1993, p.3) is seen as 'a non-native speaker's use and acquisition of linguistic action patterns in a second language'. Kasper and Schmidt (1996) claim that it has been modeled on cross-cultural pragmatics. There is a long list of researchers that have done crosssectional or longitudinal studies on interlanguage pragmatics attempting to explain and define it but it was Kathleen Bardovi-Harling (1999) who showed her doubts that explaining and defining it makes it an acquisitional endeavor. Following this issue Barron (2003) in her book 'Acquisition in Interlanguage Pragmatics' presented valuable information for the process of acquisition of pragmatic competence as well as the development of pragmatic competence, which is an area of research neglected in interlanguage pragmatics.

Crystal (1985, p. 240) provides us with a broad definition that "pragmatics is the study of language from the point of view of users, especially of the choices they make, the constraints they encounter in using language in social interaction and the effects 
Journal of Foreign Language Teaching and Applied Linguistics

their use of language has on other participants in the act of communication." According to Crystal's definition it is not only speech acts that are crucial for the successful communication but also the social context of discourse such as power and politeness, use of metaphor and irony, etc.

The Common European Framework of Reference for Languages (Council of Europe, 2001) also addresses this issue. In the CEFR the communicative language competences include linguistic, sociolinguistic and pragmatic competences. The CEFR identifies the following matters as sociolinguistic competences: linguistic markers of social relations, politeness conventions, expressions of folk-wisdom, register differences, and dialect and accent. Pragmatic competence itself includes learner's knowledge of the principles according to which messages are: a. organized, structured and arranged (discourse competence); b. used to perform communicative functions (functional competence); c. sequenced according to interactional and transactional schemata (design competence) (Council of Europe, 2001, p.123).

\section{Interlanguage pragmatics issues}

The significance of pragmatic competence has been addressed by many researchers in the field of second/foreign language acquisition, but it is evident that the awareness level of the practitioners in language teaching is still on a critical low level. Studies have shown (Thomas, 1983, p. 97) that native speakers consider grammatical and lexical mistakes normal and expected but they tend to assume that learners possess the same pragmatic norms and respond in the same way as they would. The main pragmatic issues that often occur are misunderstandings between the speakers, participating in a conversation as a listener (backchannelling), understanding metalanguage and metapragmatics, understanding the unsaid and assessing the unsaid, avoiding a speech act to accommodate a target culture norm, nonverbal behavior.

\section{Components for testing interlanguage pragmatics}

In order to collect data and test the pragmatic competence a methodological method is required to be set. A probably most accurate and ideal method to test the pragmatic competence of L2 learners is to compare their comprehension and production to the one of native speakers. Roever (2005) chose three components for his web-based language pragmatics test: speech acts, implicatures and routines. Numerous cross-cultural pragmatic studies have been conducted for empirical research purposes to study speech acts such as requests, apologies, refusals, complaints and suggestions, among many others (Beebe et al., 1990; Blum-Kulka, 1982; Cohen et al., 1986; Gass \& Neu, 1996; House \& Kasper, 1987; Ikoma, 1993; Kasper, 1989; Olshtain \& Weinbach, 1987; Takahashi \& Beebe, 1987, 1993; Trosborg, 1995). 151 


\section{Test development for interlanguage pragmatic assessment}

Pragmatic competence is understood as "the knowledge of the linguistic resources available in a given language for realizing particular illocutions, knowledge of the sequential aspects of speech acts, and finally, knowledge of the appropriate contextual use of the particular language's linguistic resources" (Barron, 2003 p.10). Thus defined, pragmatic competence includes the ability to perform language functions and the knowledge of socially appropriate language use.

Although it may seem that conversation, in which speech acts are embedded, is unsystematic, it is rulegoverned by social and cultural rules. Social and cultural rules dictate the strategies and the linguistic means used in the given context. Yet, there are a number of tests that focus on one or the other (Hudson et al., 1995; Roever, 2005, 2006b; Bouton, 1988, 1994, 1999). As McNamara (2006) put it, we have to "keep it social, but practical." Given that pragmatics is a fairly broad area, it is difficult to design a single test that assesses the entirety of a learner's pragmatic competence. Again, in analogy to testing in general, it is possible to attain broader content coverage and test an appreciable chunk of pragmatic competence by using a test battery, but testing pragmatic competence as a whole is just as complex, time-consuming, and impractical as it would be to test language competence as a whole. Depending on the purpose of the test, different aspects of pragmatic competence can be tested. (McNamara, 2006, p. 65)

However, because pragmalinguistics and sociopragmatics are closely related, it is difficult to design a test that tests exclusively pragmalinguistics or sociopragmatics. Our view is that assessment of pragmatic competence must include both.

In the process of preparing the testing of the speech acts there are several points that have normally become essential in the process of preparation of testing the pragmatic competence. The power of the speaker and the listener, the social distance between the speaker and the listener with respect to familiarity and solidarity, and the degree of imposition caused by the speech act situation are the three sociocultural variables of concern.

\section{Instruments for assessing interlanguage pragmatic ability}

There are several instrument widely accepted and used by researchers for testing pragmatic competence, such as Discourse Completion Task (DCT), roleplays, interviews, multiple choice questionnaires, corpus data. In this section of our paper we discuss the instruments and methods that we used for assessing the pragmatic competence of English and German language learners. Since assessment of L2 pragmatics has tended to focus on speech acts, for the purpose of our research project, we also limit ourselves to speech acts. We will refer to 1 . some instruments used to measure pragmatic competence, 2. context parameters, i.e. the setting in which the speech act takes place, 3. the importance of authenticity and 4. the importance of retrospection.

The studies that we have looked at have most often used DCTs, oral or written, and role plays, for assessing learners' pragmatic competence. Native-speaker performance is the benchmark against which we are judging nonnative speech act performance. The very fact that the field of language pragmatics continues to develop means that 152 
Journal of Foreign Language Teaching and Applied Linguistics

paradigms continue to shift and consequently language assessment measures must be constructed consistent with the newly emerging patterns. So, the question remains as to whether it is possible to construct a language assessment measure that accurately determines success at performance of speech acts. And in a truly sociolinguistic fashion, we would have to respond, "It depends" (Boxer \& Cohen, 2004, p.323).

The responses will be rated for: (1) ability to use the correct speech act; (2) typicality of expressions; (3) appropriateness of amount of speech and information given; (4) level of formality; (5) directness; and (6) politeness

\section{Discourse Completion Task (DCT)}

DCTs are the most criticized, but the most frequently used type of instrument for measuring pragmatic competence. DCTs are attractive because they "elicit something akin to real-world speech act performance and because they are still somewhat practical despite the need for rating at least they can be administered to large numbers of test takers at the same time." (McNamara, 2006, p.65) Although there are many claims that DCTs do not replicate reality, and people do not use DCT responses in the same way that they use language in real-life communication, there are certain aspects that can be assessed with this instrument. McNamara (2006, p.67) points out that "although DCTs (and most multiple choice measures) measure knowledge and do not allow direct predictions of real-world performance, they can be thought of as measuring potential for performance, as knowledge is arguably a necessary precondition for performance."

The DCT that we used for assessing our language learners' pragmatic competence consists of three parts referring to the three distinct speech acts: requests, apologies and complaints. In constructing the section on requests, we referred to the studies of Blum-Kulka, \& Olshtain (1984), Economidou-Kogetsidis \& Woodfield (2012), and Olshtain \& Cohen (1990); for apologies we referred to Blum-Kulka, \& Olshtain (1984), Ogiermann (2009), and Trosborg (1995); while for complaints we referred to Trosborg (1995).

In order to eliminate any weaknesses the DCT was piloted with 20 students. After doing the DCT, the students were asked to provide Yes/No responses to the following statements:

1. The information provided in the situation is sufficient (enough).

2. The situation and the roles of the participants in the conversation are clear.

3. The situations reflect possible everyday situations.

4. The context of the situation is appropriate for Macedonian students.

5. The following situations should be removed from the list: apologies - /requests - / complaints -

6. The following situations need improvement: apologies - /requests - /complaints -

On the basis of the students' remarks we concluded that:

- some of the situations needed further clarification about the relationship between the speaker and the hearer, e.g. if they are friends, how close they are; if they are acquaintances how well they know each other;

- the instructions required students to say something in each of the situations. 153 
Assessing Pragmatic Competence Of L2 Learners

However, they felt that in some of the situations which were supposed to trigger complaints or apologies they would just opt out;

- there were a few problems with vocabulary, e.g. dent in the fender;

- there were two situations that many of the students did not understand and had to be rephrased.

\section{Role plays}

In comparison with DCTs, role plays are more similar to real life speech situations. As in real conversation "there is a distributed responsibility among interlocutors for the creation of sequential coherence, identities, meaning, and events." (McNamara, 2006, p. 46). The context that they provide is more detailed, there are two interlocutors and their roles are described more precisely. There is also a moment of surprise. Although a great deal of the talk is predicted, the hearer cannot be sure what strategies, formulaic expressions and other linguistic means the speaker will use. The hearer may also be surprised by the attitude projected by the speaker and may need to adapt and modify its own responses in compliance with it. Interlocutors have to apply conversational strategies such as language planning, asking for clarification, conversation management, etc. All these characteristics make conversations look more like conversations in real life. Still, it cannot establish context as in real world. There is nothing at stake, the face of the speaker and the hearer is not really threatened, speakers may be bolder and risk more than in real life.

There are, however, a few drawbacks in the realization of the role plays. It is more difficult to organize and manage the process of data collection. It is difficult to keep track of a large number of students and ensure that students doing a role play are of the same level of proficiency. It is also time consuming and difficult to transcribe the conversations. Most of the students found the role plays interesting. Yet, there were some who found it stressful.

In our research, we used nine role plays, three for each of the speech acts. It would be interesting to compare the results from the DCT with the results from the role plays. In the following stages of our project it is intended to do so.

\section{Retrospective verbal report}

Kasper \& Dahl (1991) called attention to the usefulness of retrospective verbal report for better determining the nature of possible transfer from L1 norms of speech behavior in nonnative L2 speech act performance. The aim of such interview is to check if the students are aware of the norms of interaction in a given context: power, social distance and severity of offence/degree of imposition. Additionally we can check if the students are aware of the norms of interaction in the English and Macedonian culture (positive politeness/negative politeness; directness/indirectness) as well as how the actual environment influences their behavior (classroom, not natural environment). We made the following list of questions for this retrospective interview which immediately followed the role plays: 154 
Journal of Foreign Language Teaching and Applied Linguistics 1. Are you happy with how you formulated your speech act? What were you influenced by? (setting, description of the situation, perceived relationship, perceived power/ social distance/ degree of imposition/offence, classroom environment, pressure of being taped, your interlocutor's behavior, what you thought you were expected to say, etc.)

2. Do you think you might want to alter what you have said? Why?

3. Would you say the same if your interlocutor's role was different (professor/friend/ neighbor/ mother/brother/sister)? What would you say in that case? Why?

4. Do you think if you were speaking to a native speaker of English you would say something different? Why?

5. Do you think a native speaker would formulate their request/apology/complaint in the same way? How would it be different? Why would s/he formulate it that way?

6. What would you say if you were speaking to a Macedonian speaker? How different is it from what you said to an English speaker? What is the difference a result of?

7. Which speech act do you find the easiest/most difficult to produce? Why?

This kind of data can be instrumental in better understanding the products of such elicitation techniques. We may learn how the respondents actually perceived each situation (e.g. how they perceived the role status of the interlocutors, the imposition, seriousness of the offence, etc.), and how their perceptions influenced their responses, what they wanted to say vs. what they actually said, how they planned out their responses, and what they thought of going through the tasks altogether.

\section{Conclusion}

In this paper we discussed pragmatic competence, components relevant for its development, and some instruments for pragmatic competence assessment. In particular, we focused on speech acts. We described the battery of tasks that we developed for our project as well as their advantages and drawbacks. In the next stage of the project, we will proceed to comparing learners' to native speakers' performance and compiling a syllabus for speech act acquisition.

The project referred to in this paper was motivated by the lack of valid data on communicative competences of Macedonian learners of English and German as well as by the need of tracing effective methods for reinforcing communication skills. The research will include contrastive analysis of speech acts, design of instruments for pragmatic competence assessment and design of learning modules for developing pragmatic competence. The project anticipates placement of the learning modules on the Internet, thus making them available for the learners. The analysis of learners' pragmatic competence after studying the modules will show to what extent explicit instruction can reinforce their communication ability. We believe that with this the project will make great contribution to the development of language learners' communication skills. 155 
Assessing Pragmatic Competence Of L2 Learners

References

Bachman, L. (1990). Fundamental considerations in language testing. Oxford: Oxford University Press.

Bardovi-Harlig, K. (1999). Exploring the interlanguage of interlanguage pragmatics: A research agenda for acquisitional pragmatics. Language Learning 49, 677-713.

Barron, A. (2003). Acquisition in interlanguage pragmatics. Amsterdam: John Benjamins Publishing Company.

Blum-Kulka, S. (1987). Indirectness and politeness: Same or different? Journal of Pragmatics 11 (2), 131-146.

Blum-Kulka, S. (1992). The metapragmatics of politeness in Israeli society. In R. J. Watts, S. Ide, \& K. Ehlich, Politeness in language: Studies in its history, theory and practice (pp. 255-280). Berlin: Mouton de Gruyter.

Blum-Kulka, S., House, J., \& Kasper, G. (1989). Cross-cultural pragmatics: requests and apologies. Norwood: Ablex Publishing Corporation.

Boxer, D., \& Cohen, A. D. (2004). Studying speaking to inform second language learning. Clevedon: Multilingual Matters Ltd.

Cohen, A. D. (2004). Assessing speech acts in a second language. In D. Boxer, \& A. D. Cohen, Studying speaking to inform second language learning (pp. 302-327). Clevedon/Buffalo/Toronto: MULTILINGUAL MATTERS LTD.

Cohen, A. D., \& Ishihara, N. (2005). A web-based approach to strategic learning of speech acts. Minneapolis, MN: Center for Advanced Research on Language Acquisition, University of Minnesota.

Cohen, A. D., \& Ishihara, N. (2005). Strategies for learning and performing L2 speech acts. Intercultural Pragmatics 2 (3), 275-301.

Coulmas, F. (1981). Poison to your soul: Thanks and apologies contrastively viewed. In Conversational Routine (pp. 69-91). The Hague: Mouton.

Council of Europe. (2001). Common European Framework of Reference for Languages: Learning, teaching, assessment. Cambridge: Cambridge University Press.

Crystal, D. (1985). A dictionary of linguistics and phonetics. 2nd edition. New 156 
York: Basil Blackwell.

Journal of Foreign Language Teaching and Applied Linguistics

Faerch, C., \& Kasper, G. (1983). Strategies in interlanguage communication. London: Longman.

Fraser, B. (2010). Pragmatic competence: The case of hedging. In G. Kaltenböck, W. Mihatsch, \& S. Schneider, New Approaches to Hedging (pp. 15-34). Bingley: Emerald.

Hinkel, E. (2011). Handbook of research in second language teaching and learning. New York, NY: Routledge.

Holmes, J. (1990). Apologies in New Zeland English. Language in Society, Vol. 19, No. 2, 155-199.

Ishihara, N., \& Cohen, A. (2010). Teaching and learning pragmatics: Where language and culture meet. London: Longman.

Kusevska, M. (1997). Speech acts: The act of complaining in English and Macedonian. MA-TESL thesis. Tempe, AZ, USA: Arizona State University.

Liu, J. (2004). Measuring interlanguage pragmatic knowledge of Chinese EFL learners. PhD dissertation. City University of Hong Kong.

McConachy, T., \& Hata, K. (2013). Addressing textbook representations of pragmatics and culture. ELT Journal 67 (3), 294-301.

McNamara, T. F., \& Roever, C. (2006). Language testing: The social dimension. Oxford, UK: Basil Blackwell.

O'Keeffe, A., Clancy, B., \& Adolphs, S. (2011). Introducing pragmatics in use. London/New York: Routledge.

Olshtain, E., \& Blum-Kulka, S. (1985). Cross-cultural pragmatics and the testing of communicative competence. Language Testing 2 (1), 16-30.

Roever, C. (2005). “That's not fair!” Fairness, bias, and differential item functioning in language testing. University of Hawaii.

Ross, S., \& Kasper, G. (2013). Assessing second language pragmatics. New York, NY: Palgrave Macmillan.

Thomas, J. (1983). Cross-cultural pragmatic failure. Applied Linguistics 4 (2), 91-112.157 
Assessing Pragmatic Competence Of L2 Learners

Trosborg, A. (2010). Pragmatics across languages and cultures. Berlin, New York: Walter de Gruyter $\mathrm{GmbH} \& \mathrm{Co}$. KG.

Wigglesworth, G., \& Yates, L. (2007). Mitigating difficult requests in the workplace: What learners and teachers need to know. TESOL Quarterly 41, 791-803.

Yamashita, S. (2008). Investigating interlanguage pragmatic ability: What are we testing? In E. Soler, \& A. Martinez-Flor, Investigating pragmatics in foreign language learning, teaching and testing (pp. 201-223). Bristol/Buffalo/Toronto: MULTILINGUAL MATTERS.158 